\title{
Expansão da Fronteira Agrícola e suas relações com o Trabalho Análogo a de Escravo no Nordeste da Bahia ${ }^{1}$
}

\author{
Elen da Silva Coutinho ${ }^{2}$ \\ Guiomar Inez Germani ${ }^{3}$ \\ Gilca Garcia de Oliveira ${ }^{4}$
}

Desde 1930, o Brasil é signatário dos acordos e convenções da Organização Internacional do Trabalho (OIT) referentes ao combate ao trabalho análogo a de escravo. No entanto, a presença desta prática só foi reconhecida no País, no ano de 1995, no emblemático caso Zé Pereira que resultou em processo junto a Organização dos Estados Americanos (OEA) que exigia que fossem tomadas medidas para o combate deste crime (Oliveira et al, 2011).

Existe um marco jurídico nacional que estabelece como crime submeter qualquer trabalhador a condições análogas a de escravo. O artigo 149 do Código Penal Brasileiro considera como "trabalho análogo a de escravo" toda a condição de trabalho, mesmo que provisória, que apresente jornada forçada ou exaustiva; a coação física ou moral; privação da liberdade e da locomoção; que seja realizado em condições degradantes e sem garantia de direitos, com pena de reclusão, de dois a oito anos, mais multa.

\footnotetext{
${ }^{1}$ Este estudo foi apoiado por uma bolsa PIBIC vinculado ao Projeto "Expansão territorial do capital, campesinato e conflitos, no Oeste da Bahia".

${ }^{2}$ Membro do Grupo GeografAR/FCE/UFBA

${ }^{3}$ Professora do Programa de Pós-Graduação em Geografia/UFBA, Lider do Grupo de Pesquisa Projeto GeografAR

${ }^{4}$ Professora dos Programas de Pós-Graduação em Economia e em Geografia/UFBA. Grupo de Pesquisa Projeto GeografAR.
}

Brasiliana - Journal for Brazilian Studies. Vol. 2, n.2 (Nov 2013). ISSN 2245-4373. 
Não obstante, consta nos registros da Lista Suja do Trabalho Escravo ${ }^{5}$ que 38.515 trabalhadores foram resgatados do trabalho análogo a de escravo, no período de 2003 a 20136, no País.

Em tempos de globalização, pode surpreender a constatação de que concomitante a implantação de processos de produção com o uso intensivo de tecnologias, empregos com modernas concepções com exploração da força de trabalho, coexista a máxima exploração da força de trabalho em condições degradantes consideradas análogas a de escravo. Trabalhadores escravizados sem os grilhões da escravidão tradicional, mas submetidos a trabalhos forçados, jornada exaustiva, condições degradantes de trabalho e em muitos casos, cativos de dívidas forjadas que "substituem" os grilhões no estágio atual do sistema capitalista.

Oliveira et al. (2011) relatam que as condições se tornaram mais perversas na "nova" escravidão, uma vez que são as condições de extrema vulnerabilidade social, a miséria e a ausência de oportunidades de trabalho que levam os trabalhadores a se sujeitarem às condições degradantes de trabalho, muitas vezes, com o histórico apelo à migração. Não existe mais a figura do "capitão do mato", mas na escravidão contemporânea existe o "gato", intermediário na cooptação de trabalhadores, na coação e na violência. Nesse novo contexto, o trabalhador nem mesmo conhece seu empregador, aquele que verdadeiramente o sujeita às condições degradantes de trabalho. É um dado relevante que cerca de $70 \%$ dos trabalhadores resgatados se concentram nas atividades do campo, isolados, afastados dos olhos a sociedade.

\footnotetext{
${ }^{5}$ A denominada Lista Suja do trabalho escravo elaborada pelo Ministério do Trabalho e Emprego é um cadastro de empregadores que tenham submetido trabalhadores a condições análogas a de escravo, é atualizada semestralmente para inclusão ou exclusão de infratores. A Lista Suja do trabalho escravo pode ser acessada em http://portal.mte.gov.br/trab_escravo/portaria-do-mte-cria-cadastro-de-empresas-e-pessoas-autuadas-por-exploracaodo-trabalho-escravo.htm.

${ }^{6}$ Os dados são referentes à Lista Suja e complementados com informações das fiscalizações de rotina. O período a que se referem vai de 2003 a julho de 2013.
}

Brasiliana - Journal for Brazilian Studies. Vol. 2, n.2 (Nov 2013). ISSN 2245-4373. 
Este artigo trata da expansão territorial do capital e a relação com trabalho análogo à de escravo, no Oeste baiano - aqui considerado como os Territórios de Identidade Bacia do Rio Corrente ${ }^{7}$ e Bacia do Rio Grande ${ }^{8}$ região com maior incidência de casos no Estado, tanto no número de trabalhadores resgatados quanto de empregadores infratores e, ao mesmo tempo, região economicamente dinâmica e polo da expansão do agronegócio na Bahia.

Este trabalho é desenvolvido no âmbito do Grupo de Pesquisa GeografAR (POSGEO/FCE/UFBA/CNPq) e vinculado à pesquisa “Diagnóstico e Mapeamento do Trabalho Escravo na Bahia". Neste artigo faz-se um recorte analítico dos municípios do Oeste Baiano e nestes municípios destacam-se aqueles onde há registro de ocorrência de trabalho escravo9.

\section{Expansão da Fronteira Agrícola no Oeste Baiano}

Localizado em uma área de 14 milhões de hectares e caracterizado por uma bacia hidrográfica com potencialidade para irrigação, composta por rios perenes e grande volume de água, o Oeste Baiano está geograficamente inserido na região mais rica em recursos hídricos do Nordeste Brasileiro.

\footnotetext{
${ }^{7}$ O Território de Identidade Bacia do Rio Corrente é composto pelos municípios de: Brejolândia, Canápolis, Cocos, Coribe, Correntina, Jaborandi, Santa Maria da Vitória, Santana, São Félix do Coribe, Serra Dourada, Tabocas do Brejo Velho.

${ }^{8}$ O Território de Identidade Bacia do Rio Grande é comporto pelos municípios de: Angical, Baianópolis, Barreiras, Buritirama, Catolândia, Cotegipe, Cristópolis, Formosa do Rio Preto, Luiz Eduardo Magalhães, Mansidão, Riachão das Neves, Santa Rita de Cássia, São Desidério, Wanderley.

${ }^{9}$ Municípios do Oeste Baiano com ocorrência de Trabalho Escravo: São Desidério, Barreiras, Correntina, Luis Eduardo Magalhães, Baianópolis, Cocos, Cotegipe, Cristópolis, Formosa do Rio Preto, Jaborandi, Riachão das Neves, Santa Rita de Cássia, Wanderley.
}

Brasiliana - Journal for Brazilian Studies. Vol. 2, n.2 (Nov 2013). ISSN 2245-4373. 
Até a década de 1970, era uma área, praticamente, desconectada economicamente da área mais dinâmica do Estado. Era o "além São Francisco". A partir desta data, teve início um intenso programa governamental para a ocupação produtiva das terras do Cerrrado em outros moldes. Nas décadas de 1980 e 1990, observa-se na região uma expansão agropecuária intensa e, devido ao acréscimo significativo na produção de grãos, de cultivos perenes e da agricultura irrigada, introduziram-se grandes transformações, principalmente no que se refere ao uso e ocupação do solo. O Oeste Baiano tornou-se a principal fronteira agrícola do Estado aberta ao capital nacional e internacional. O desenvolvimento produtivo dessa região fez da Bahia um importante produtor nacional de grãos, café, carnes, frutas e fibras (Mendonça, 2006). Em Nota Técnica do governo baiano afirma que:

O Oeste da Bahia, até a década de 1970, caracterizava-se por um modelo de agricultura de subsistência baseado nas culturas de milho, feijão e arroz, ao lado de uma pecuária extensiva. A partir da década de 80, com a implantação e expansão da sojicultura, a região ganha uma nova dinâmica de desenvolvimento, inserindo-se de forma progressiva e competitiva na estrutura produtiva estadual e nacional, notabilizandose como principal área produtora de grãos do Nordeste brasileiro, com a consolidação não só da cultura da soja, como do milho, do arroz, do feijão e, mais recentemente do algodão e do café de qualidade (Bahia, $\mathrm{s} / \mathrm{d})$.

A expansão da agricultura no Oeste Baiano, vinculada ao agronegócio, é resultado da combinação de condições edafoclimáticas favoráveis e amplo investimento em recursos tecnológicos modernos: sistemas de irrigação; mecanização das lavouras; utilização de 
sementes desenvolvidas especificamente para as condições do Cerrado e um programa de créditos e infraestrutura viária viabilizado com uma ação concentrada e direcionada pelo Estado.

\section{Estrutura fundiária}

Segundo Germani (2005), as condições históricas e sociais que regularam a ocupação do espaço agrário brasileiro geraram e consolidaram uma estrutura de propriedade das mais concentradas do mundo. Uma imensidão de terras sem uso algum e uma legião de agricultores sem trabalho, sem terras. E no Oeste Baiano não foi diferente.

Segundo Santos e Oliveira (2012), a concentração de terras na Bahia pouco se modificou no período de 1970 a 2006. Ocorreu um intenso processo de mecanização nas atividades produtivas no campo, principalmente a partir de 1980, reflexo do processo de "modernização" agrícola que se evidenciou em todo o País. O campo baiano caracteriza-se por um grande número de estabelecimentos rurais ocupando pequenas áreas, enquanto um reduzido número de estabelecimentos ocupa a maior parte da área total. Segundo os dados do Censo Agropecuário de $2006^{10}$, tem-se que, no Estado da Bahia, os estabelecimentos no grupo de área com até 10 ha correspondem a $59,85 \%$ e detêm $4,69 \%$ da área enquanto os estabelecimentos com mais de 1.000 ha correspondem a 0,45\% dos estabelecimentos e ocupam 35,61\% da área do Estado.

A Tabela 1 apresenta o Índice de Gini ${ }^{11}$ para a Bahia, na série histórica de

\footnotetext{
${ }^{10}$ A estrutura da propriedade da terra pode ser dimensionada através dos dados do Instituto Nacional de Colonização e Reforma Agrária (INCRA) e/ou do Instituto Brasileiro de Geografia e Estatística (IBGE). Além do diferencial na forma de coleta das informações, estas instituições usam bases conceituais distintas: a primeira é declaratória e tem como referência o "imóvel rural" e a segunda é censitária e tem como referência o "estabelecimento rural". Optou-se trabalhar com os dados do IBGE por serem estas informações utilizadas pelo GeografAR e assim servir como base para comparação dos resultados.

${ }^{11}$ Indicador que mede a distribuição de um dado bem, nesse caso a terra. Os valores mais próximos de um Brasiliana - Journal for Brazilian Studies. Vol. 2, n.2 (Nov 2013). ISSN 2245-4373.
} 
1970 a 2006. Observa-se que a concentração das terras no Estado tem se mantido bastante elevada, ocorrendo, inclusive, acentuação neste período. A partir de 1975 atinge a casa de 0,8 e não reduz mais deste valor, chegando a 0,838, em 2006.

Tabela 1 Índice de Gini da Terra, Bahia, 1970-2006

\begin{tabular}{cc}
\hline Ano & Índice de \\
\hline 1970 & 0,795 \\
1975 & 0,805 \\
1980 & 0,821 \\
1985 & 0,835 \\
$1995 / 96$ & 0,829 \\
2006 & 0,838 \\
\hline
\end{tabular}

Fonte: Censo Agropecuário/IBGE, 1970/2006. Elaborado por Projeto GeografAR (2010).

A alta concentração da propriedade da terra revela uma situação de vulnerabilidade propícia a conflitos e exploração, pois está diretamente relacionada às limitadas ocupações e empregos no campo. A baixa oferta de trabalho no campo abre espaço para a exploração dos trabalhadores em sua expressão mais degradante: o trabalho análogo a de escravo.

No Oeste da Bahia tem se expandido a fronteira agrícola com intensa ocupação das terras e é neste espaço onde vem se observando o maior número de trabalhadores resgatados em condições análogas a de escravo na Bahia.

Nos municípios do Oeste baiano com ocorrência de trabalho escravo verificou-se uma acentuada expansão da fronteira agrícola concomitante com acentuação da concentração de terras nas propriedades com áreas acima de 500 hectares (Tabela 2).

Os dados na Tabela 2 permitem ver que, em 1970, os estabelecimentos do grupo de área de até 50 ha representavam 78,83\% dos estabelecimentos e ocupavam 26,75\% da 
área. Em 2006 este percentual diminui passando a 67,89\% dos estabelecimentos e ocupando 11,05\% da área. No mesmo período o percentual dos estabelecimentos de 50 a 500 ha permaneceu praticamente o mesmo - de 19,28\% a 18,55\% -, enquanto que, em termos de área caiu pela metade - de 36,81\% a 14,58\%. Nas áreas acima de 500 ha o percentual de estabelecimentos quadruplicou - de 2,13\% para $8,35 \%$ - e dobrou o percentual de área - passando de 36,64\% para 79,93\%. Estes dados revelam que a expansão para o Oeste se deu com a consolidação de grandes áreas destinadas ao agronegócio.

Tabela 2 Estrutura Fundiária dos municípios do Oeste baiano com ocorrência de Trabalho Escravo. 1970 a 2006

\begin{tabular}{|c|c|c|c|c|c|c|}
\hline \multirow{2}{*}{$\begin{array}{c}\text { Censo } \\
\text { Agropecuário } \\
\text { IBGE }\end{array}$} & $\begin{array}{c}|c| \\
\text { Até } 50 \text { ha }\end{array}$ & \multicolumn{2}{c|}{ De 50 a 500 ha } & \multicolumn{2}{c|}{ Acima de 500 ha } \\
\cline { 2 - 6 } & $\begin{array}{c}\text { Estabelecimento } \\
(\%)\end{array}$ & $\begin{array}{c}\text { Área } \\
(\%)\end{array}$ & $\begin{array}{c}\text { Estabelecimento } \\
(\%)\end{array}$ & $\begin{array}{c}\text { Área } \\
(\%)\end{array}$ & $\begin{array}{c}\text { Estabelecimento } \\
(\%)\end{array}$ & $\begin{array}{c}\text { Área } \\
(\%)\end{array}$ \\
\hline 1970 & 78,83 & 26,75 & 19,28 & 36,81 & 2,13 & 36,64 \\
1980 & 72,05 & 10,36 & 23,32 & 18,58 & 5,25 & 70,97 \\
1996 & 72,44 & 11,05 & 22,07 & 17,13 & 6,34 & 72,67 \\
2006 & 67,89 & 11,05 & 18,55 & 14,58 & 8,35 & 79,93 \\
\hline
\end{tabular}

Fonte: IBGE, 2006. Elaboração própria.

Nery et al. (2011) destacam o comportamento dos dados da estrutura fundiária do município de São Desidério, na série histórica de 1970 a 2006, município que mais registra ocorrências de "trabalho escravo" no estado da Bahia. No Quadro 1 pode-se observar que, em 1970, os estabelecimentos de até 50 ha representavam 95,01\% do total dos estabelecimentos do município e detinham 21,27\% da área. Enquanto que, as propriedades com mais de 500 ha representavam apenas $0,63 \%$ com 62,99\% de extensão territorial. Em 1980, as propriedades de até 50 ha reduziram o percentual de estabelecimento área, para 87,1\% e 3,33\% respectivamente; ao contrário das acima de 500 ha que, neste ano, aumentaram e passaram a representar 2,75\% dos estabelecimentos, 
detendo 90,09\% da área. Essa tendência de crescimento segue não somente em São Desidério, mas em outros municípios do Extremo Oeste, como: Barreiras, Correntina, Jaborandi, Formosa do Rio Preto, e outros. Ainda em São Desidério, a título de comparação, no Censo Agropecuário de 2006, as propriedades menores de 50 ha representavam $63,57 \%$ das propriedades, possuindo essas apenas 1,73\% de extensão territorial; enquanto as grandes, acima de 500 ha passaram a 13,49\% dos estabelecimentos e detendo o correspondente a $93,67 \%$ da área. Os estabelecimentos do grupo de área de 50 a 500 ha diminuíram a participação no percentual da área ocupada, sendo que aumentou o número de estabelecimentos nesse grupo de área e em valores absolutos a área ocupada por esses estabelecimentos também aumentou.

Quadro 1 Série histórica da estrutura fundiária de São Desidério (BA). 1970 a 2006.

\begin{tabular}{|c|c|c|c|c|c|c|}
\hline \multirow{2}{*}{ ANO } & \multicolumn{2}{|c|}{ Até 50 ha } & \multicolumn{2}{c|}{ de 50 a 500ha } & \multicolumn{2}{c|}{ Acima de 500 ha } \\
\cline { 2 - 7 } & $\begin{array}{c}\text { Estabelecimento } \\
(\%)\end{array}$ & $\begin{array}{c}\text { Área } \\
(\%)\end{array}$ & $\begin{array}{c}\text { Estabelecimento } \\
(\%)\end{array}$ & $\begin{array}{c}\text { Área } \\
(\%)\end{array}$ & $\begin{array}{c}\text { Estabelecimento } \\
(\%)\end{array}$ & $\begin{array}{c}\text { Área } \\
(\%)\end{array}$ \\
\hline 1970 & 95,01 & 21,27 & 4,36 & 15,73 & 0,63 & 62,99 \\
\hline 1980 & 87,1 & 3,33 & 10,23 & 6,60 & 2,75 & 90,09 \\
\hline 1996 & 73,7 & 1,25 & 12,40 & 3,63 & 13,9 & 95,11 \\
\hline 2006 & 63,57 & 1,73 & 15,83 & 4,61 & 13,49 & 93,67 \\
\hline
\end{tabular}

Fonte: Censo Agropecuário IBGE de 1970, 1980, 1996 e 2006. Elaboração própria com base em Nery et. al, 2011.

Conforme esses dados a redução das pequenas propriedades ocorre devido ao crescimento, em ritmo e escala ampliada, das grandes propriedades confirmam que "a estrutura fundiária pode ser entendida como a representação numérica da dimensão da violência manifestada pela apropriação privada da natureza no modo de produção capitalista" (Germani, 2010, p. 275). Grilagem, roubo, violência aberta, entre outros métodos são partes constituintes desse processo. Aliado a isso se tem o fato de ser nessa região onde se encontra um grande percentual estimado de terras devolutas. 


\section{Estrutura Produtiva}

Dados da Pesquisa Agrícola Municipal (PAM) do IBGE revelam a expansão da fronteira agrícola dos municípios do Oeste baiano, no período de 1990 a 2010 que pode ser visualizada através da área plantada no período (Tabela 3). As culturas que mais cresceram em área plantada e valores da produção foram: soja; algodão herbáceo; milho; feijão; mandioca; arroz e cana-de-açúcar. Na Tabela 4, onde se apresenta os dados do valor de produção, pode-se observar que essas culturas foram responsáveis por mais de 90\% do valor da produção em 1990, 2000 e $2010^{12}$.

Entre essas culturas, a soja ocupa posição de destaque concentrando mais de $60 \%$ da área plantada desde o início da série. A área plantada da soja cresceu $182 \%$ no período, mas diminui a participação na área plantada total, passando de aproximadamente 74\%, em 1990, para aproximadamente 63\%, em 2010. A participação da soja no valor da produção cresceu de aproximadamente 38\%, em 1990, para aproximadamente $46 \%$, em 2010 (Tabela 3).

No total, em 20 anos, a área plantada cresceu $232 \%$ no Oeste, sendo que a área plantada de arroz diminui $36 \%$, e diminuiu, também, a sua participação no valor da produção. A área plantada de cana de açúcar cresceu 26\%, mas na participação na área plantada total diminuiu de 1,43\%, em 1990, para 0,55\%, em 2010, o mesmo ocorre com a participação no valor total da produção que passa de $6,59 \%$ para $1,23 \%$.

\footnotetext{
${ }^{12} 93,3 \%$ do valor da produção em 1990; 90,7\% em 200 e 91,9\% em 2010.
}

Brasiliana - Journal for Brazilian Studies. Vol. 2, n.2 (Nov 2013). ISSN 2245-4373. 
Tabela 3 Área Plantada do Oeste Baiano, 1990 - 2010

\begin{tabular}{|c|c|c|c|c|c|c|c|}
\hline \multirow[b]{2}{*}{ PAM OESTE } & \multicolumn{3}{|c|}{ Área plantada (Ha) } & \multirow[b]{2}{*}{$\begin{array}{l}\text { Variação } \\
\%\end{array}$} & \multicolumn{3}{|c|}{ Parcela da área plantada \% } \\
\hline & 1990 & 2000 & 2010 & & 1990 & 2000 & 2010 \\
\hline $\begin{array}{l}\text { Algodão herbáceo } \\
\text { (em caroço) }\end{array}$ & 1.535 & 40.561 & 245.561 & 1.5897 & 0,32 & 4,10 & 15,16 \\
\hline Arroz (em casca) & & & & & & & \\
\hline (Toneladas) & 26.985 & 50.907 & 17.405 & -36 & 5,54 & 5,14 & 1,07 \\
\hline Cana-de-açúcar & 6.984 & 7.073 & 8.830 & 26 & 1,43 & 0,71 & 0,55 \\
\hline Feijão (em grão) & 26.162 & 38.595 & 53.442 & 104 & 5,37 & 3,90 & 3,30 \\
\hline Mandioca & 18.150 & 38.822 & 25.360 & 40 & 3,72 & 3,92 & 1,57 \\
\hline Milho (em grão) & 42.670 & 166.536 & 222.610 & 422 & 8,76 & 16,83 & 13,74 \\
\hline Soja (em grão) & 360.000 & 628.356 & 1.014 .950 & 182 & 73,88 & 63,50 & 62,67 \\
\hline Outras $^{13}$ & 4.788 & 18.723 & 31.480 & 557 & 0,98 & 1,89 & 1,94 \\
\hline Total & 487.274 & 989.573 & 1.619 .638 & 232 & 100,00 & 100,00 & 100,00 \\
\hline
\end{tabular}

Fonte: IBGE - Produção Agrícola Municipal. Elaboração Própria

A participação de algodão herbáceo na área plantada total do Oeste baiano cresceu, passando de $0,32 \%$, em 1990, para $15,16 \%$, e o valor da produção passou de 1,18\% para 25,64\%. A cultura do milho também aumentou a participação na área plantada do Oeste, de $8,76 \%$, em 1990 , para $13,74 \%$, em 2010 , a variação foi de $422 \%$ na área plantada entre as décadas. No valor da produção o aumentou foi de 4,32\% para 12,62\%. A importância das culturas mudou entre as décadas. Na década de 1990, a soja, a mandioca e o feijão eram as culturas com maior participação na área plantada e no valor da produção do Oeste baiano, em 2010, tem destaque a soja, que se mantém na liderança, algodão herbáceo e milho (Tabela 4).

\footnotetext{
${ }^{13}$ Culturas com menor participação em área plantada e valor da produção: abacate, abacaxi, alho, amendoim, banana, batata-doce, batata-inglesa, café, cebola, coco-da-baía, figo, fumo, goiaba, laranja, limão, mamão, mamona, manga, maracujá, melancia, sorgo granífero, tangerina, tomate e uva.
}

Brasiliana - Journal for Brazilian Studies. Vol. 2, n.2 (Nov 2013). ISSN 2245-4373. 
Tabela 4 Valor da Produção no Oeste Baiano, 1990 - 2010

\begin{tabular}{|c|c|c|c|c|c|c|}
\hline \multirow[b]{2}{*}{ PAM OESTE } & \multicolumn{3}{|c|}{ Valor da produção } & \multicolumn{3}{|c|}{ Valor da produção (\%) } \\
\hline & $\begin{array}{c}1990 \\
\text { (Mil } \\
\text { Cruzeiros) }\end{array}$ & $\begin{array}{c}2000 \\
\text { (Mil } \\
\text { Reais) } \\
\end{array}$ & $\begin{array}{c}2010 \\
\text { (Mil } \\
\text { Reais) } \\
\end{array}$ & 1990 & 2000 & 2010 \\
\hline Total & 6750156 & 936064 & 3599016 & 100 & 100 & 100 \\
\hline $\begin{array}{l}\text { Algodão herbáceo } \\
\text { (em caroço) }\end{array}$ & 79957 & 81006 & 922701 & 1,18 & 8,65 & 25,64 \\
\hline $\begin{array}{l}\text { Arroz (em casca) } \\
\text { (Toneladas) }\end{array}$ & 172193 & 20618 & 15769 & 2,55 & 2,20 & 0,44 \\
\hline Cana-de-açúcar & 444919 & 35158 & 45458 & 6,59 & 3,76 & 1,26 \\
\hline Feijão (em grão) & 720827 & 37101 & 167748 & 10,68 & 3,96 & 4,66 \\
\hline Mandioca & 2045293 & 120065 & 53982 & 30,30 & 12,83 & 1,50 \\
\hline Milho (em grão) & 291582 & 149306 & 454072 & 4,32 & 15,95 & 12,62 \\
\hline Soja (em grão) & 2542172 & 405903 & 1646550 & 37,66 & 43,36 & 45,75 \\
\hline Outras & 453213 & 86907 & 292736 & 6,71 & 9,28 & 8,13 \\
\hline
\end{tabular}

Fonte: IBGE - Produção Agrícola Municipal. Elaboração Própria.

Não é sem significado que, de acordo com os dados da Lista Suja, no período de 2003 a 2013, a distribuição das atividades em que se resgatou trabalhadores em condições análogas a de escravo foram: carvoaria (18\%); algodão herbáceo (17\%); preparo de terreno (13\%); milho (13\%); soja (9\%); desmatamento $(5 \%)$ e café $(5 \%)$ e outras com menor percentual.

Observa-se, assim, que, no Oeste baiano, a expansão da fronteira agrícola se dá no crescimento das culturas em que mais houve resgate de trabalhadores em condições análogas a de escravo: algodão herbáceo, milho e soja.

\section{Os Conflitos no Oeste Baiano: o Caso do Trabalho Análogo a de Escravo}

O trabalho análogo a de escravo não se resume ao campo, mas é um dado relevante que cerca de $70 \%$ dos trabalhadores resgatados se encontravem nas atividades do campo. 
No Brasil, de acordo com os dados do MTE (2009), 40\% dos trabalhadores em condição análoga a escravo encontra-se nas fazendas pecuárias, em atividades como limpeza e preparo do pasto, sendo que, as lavouras temporárias, principalmente, relacionadas ao cultivo da cana-de-açúcar, cereais, algodão herbáceo, fumo e soja, apresentaram $17 \%$ do total dos estabelecimentos com trabalhadores resgatados e a categoria produção florestal foi a terceira com aproximadamente $11 \%$ do total de trabalhadores resgatados (Oliveira et al, 2011 p. 9).

Na Bahia, de acordo com dados da Lista Suja - sintetizada na Tabela 5 e espacializados na Figura 1 -, de 2003 até julho de 2013, foram autuadas 74 propriedades, 82\% delas localizadas no Oeste baiano, região polo do agronegócio no Estado. Com maior concentração em São Desiderio (14 casos), Formosa do Rio Preto (10 casos), Barreiras (8 casos), Correntina (7 casos), Luís Eduardo Magalhães (6 casos) e Riachão das Neves (4 casos). Havendo ainda incidências em Jaborandi e Baianópolis, ambos com três casos de resgates, Sitio do Mato, Cotegipe e Barra do Choça com dois casos de resgates cada. Além de Cocos, Juazeiro, Sebastião Laranjeiras, Jandaíra, Feira de Santana, Cristópolis, Bom Jesus da Lapa, Wanderley, Encruzilhada, Santa Rita de Cássia, Salvador, Camaçari e Ilhéus, todos com um caso de resgate cada.

O maior número de trabalhadores resgatados ocorreu em São Desidério (994), seguido de Barreiras (517); Luiz Eduardo Magalhães (342); Jaborandi (293); Correntina (249) e Formosa do Rio Preto (229). No ano de 2003, em São Desidério, se deu o emblemático caso da fazenda Roda Velha Agroindustrial, de Ernesto Dias Filho, onde 745 trabalhadores foram resgatados na cultura do café, a partir de denúncias feitas pelos trabalhadores. No mesmo ano, em Luiz Eduardo Magalhães, na Fazenda Tabuleiro, com mais de 20.000 ha, de André Gomes Ribas e Constantino de Oliveira (Viação Planeta e 
Gol Linhas Aéreas), são resgatados 259 trabalhadores envolvidos na cata de raiz e limpeza de área.

Tabela 5 Lista Suja do trabalho escravo. Bahia. 2003 a 2013

\begin{tabular}{lrrrrrr}
\hline \multicolumn{1}{c}{ MUNICÍPIOS } & \multicolumn{1}{c}{ CASOS } & \% & ACUM & \multicolumn{1}{c}{ LIBER } & \multicolumn{1}{c}{$\%$} & \multicolumn{1}{c}{ ACUM } \\
\hline São Desidério & 14 & 18,92 & 18,92 & 994 & 30,18 & 30,18 \\
Formosa do Rio Preto & 10 & 13,51 & 32,43 & 229 & 6,95 & 37,13 \\
Barreiras & 8 & 10,81 & 43,24 & 517 & 15,70 & 52,82 \\
Correntina & 7 & 9,46 & 52,70 & 249 & 7,56 & 60,38 \\
Luis Eduardo Magalhães & 6 & 8,11 & 60,81 & 342 & 10,38 & 70,77 \\
Riachão das Neves & 4 & 5,41 & 66,22 & 85 & 2,58 & 73,35 \\
Baianópolis & 3 & 4,05 & 70,27 & 49 & 1,49 & 74,83 \\
Jaborandi & 3 & 4,05 & 74,32 & 293 & 8,89 & 83,73 \\
Barra do Choça & 2 & 2,70 & 77,03 & 68 & 2,06 & 85,79 \\
Cotegipe (BA) & 2 & 2,70 & 79,73 & 14 & 0,43 & 86,22 \\
Sítio do Mato & 2 & 2,70 & 82,43 & 44 & 1,34 & 87,55 \\
Encruzilhada & 1 & 1,35 & 83,78 & 63 & 1,91 & 89,47 \\
Wanderley & 1 & 1,35 & 85,14 & 22 & 0,67 & 90,13 \\
Bom Jesus da Lapa & 1 & 1,35 & 86,49 & 1 & 0,03 & 90,16 \\
Camaçari & 1 & 1,35 & 87,84 & 8 & 0,24 & 90,41 \\
Cocos & 1 & 1,35 & 89,19 & 46 & 1,40 & 91,80 \\
Cristópolis & 1 & 1,35 & 90,54 & 7 & 0,21 & 92,02 \\
Feira de Santana & 1 & 1,35 & 91,89 & 25 & 0,76 & 92,77 \\
Ilhéus & 1 & 1,35 & 93,24 & 5 & 0,15 & 92,93 \\
Jandaíra & 1 & 1,35 & 94,59 & 60 & 1,82 & 94,75 \\
Juazeiro & 1 & 1,35 & 95,95 & 12 & 0,36 & 95,11 \\
Salvador & 1 & 1,35 & 97,30 & 17 & 0,52 & 95,63 \\
Santa Rita de Cássia & 1 & 1,35 & 98,65 & 74 & 2,25 & 97,87 \\
Sebastião Laranjeiras & 1 & 1,35 & 100,00 & 70 & 2,13 & 100,00 \\
Total & 74 & $\mathbf{1 0 0 , 0 0}$ & & 3.294 & $\mathbf{1 0 0 , 0 0}$ & \\
\hline
\end{tabular}

Fonte: Brasil, 2012.

A lista de empregadores infratores - a denominada Lista Suja do trabalho escravo do Ministério do Trabalho e Emprego - é um cadastro que publiciza à sociedade os empregadores que sujeitaram seus trabalhadores a condições análogas a de escravo em suas propriedades ou empreendimentos. No entanto, após dois anos de registro o nome do empregador é retirado do cadastro, caso não haja reincidência.

Dos municípios baianos que constam na Lista Suja, observa-se que $88 \%$ 
dos resgatados se concentram nos municípios dos Territórios de Identidade da Bacia

do Rio Grande e Bacia do Rio Corrente, ou seja, dos 74 casos na Bahia, 61 foram no Oeste baiano.

\section{Figura 1:}

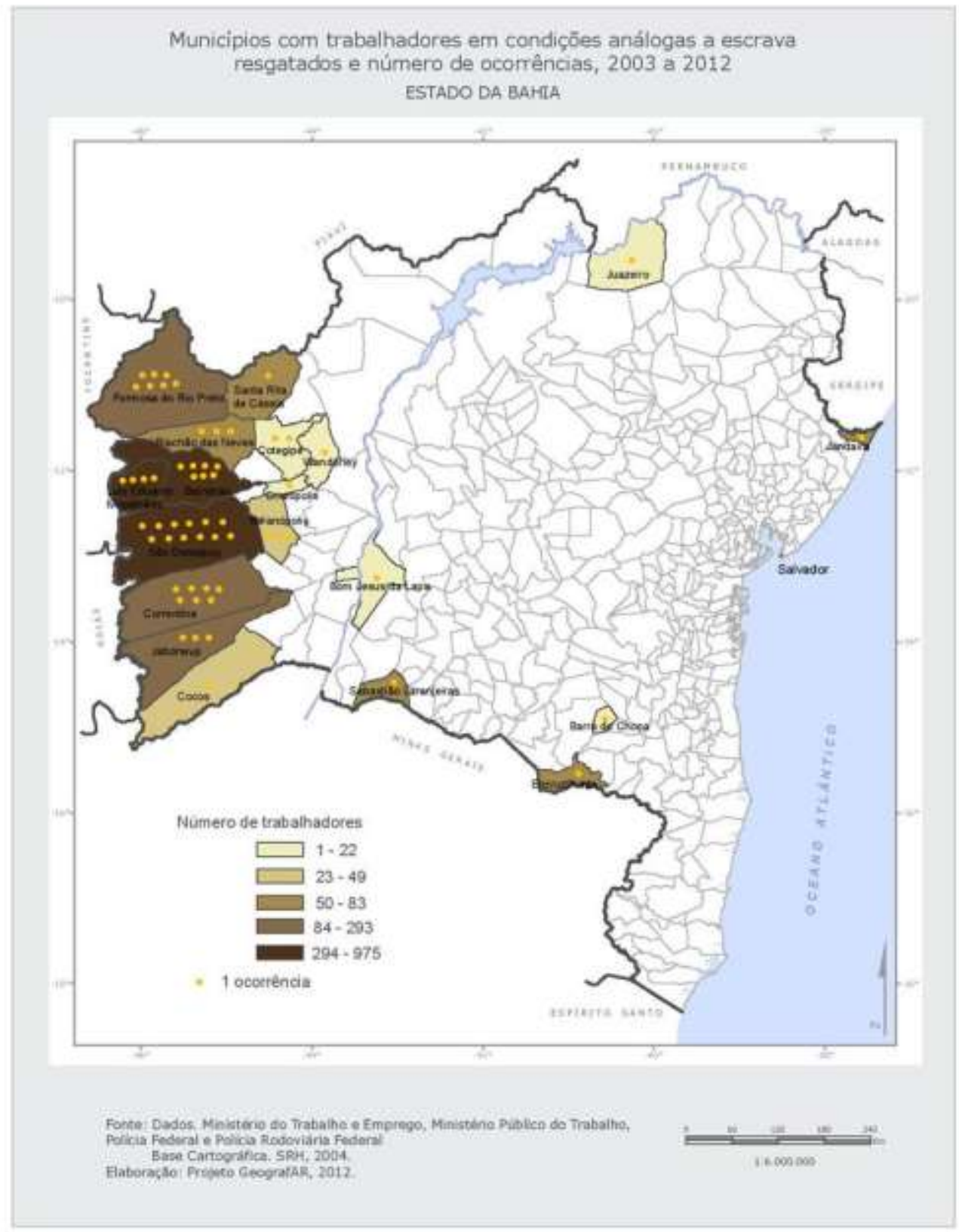

Brasiliana - Journal for Brazilian Studies. Vol. 2, n.2 (Nov 2013). ISSN 2245-4373. 
Segundo a Organização Internacional do Trabalho (OIT), o programa brasileiro de combate ao trabalho escravo é um dos mais avançados do mundo. A condição indissociável entre atividade econômica e dignidade humana permeia a legislação brasileira sobre o tema. A OIT, na Convenção nº 29, de 1930, define como trabalho forçado ou obrigatório "todo trabalho ou serviço exigido de um indivíduo sob ameaça de qualquer penalidade e para o qual ele não se ofereceu de vontade espontânea". O conceito definido pela OIT é generalista dentro do padrão das normas e convenções internacionais. Cabe a cada país, estabelecer sua própria legislação. No caso do Brasil, o conceito de trabalho análogo a de escravo, para além da definição da OIT, inclui também o conceito de dignidade humana previsto na Constituição Federal em vigor. O Código Penal, em três artigos, trata especificamente do trabalho escravo e da punição aos empregadores infratores.

Art. 149 - Reduzir alguém a condição análoga à de escravo, quer submetendo-o a trabalhos forçados ou a jornada exaustiva, quer sujeitando-o a condições degradantes de trabalho, quer restringindo, por qualquer meio, sua locomoção em razão de dívida contraída com o empregador ou preposto. Pena: reclusão, de dois a oito anos, e multa, além da pena correspondente à violência. Nas mesmas penas incorre quem: cerceia o uso de qualquer meio de transporte por parte do trabalhador, com o fim de retê-lo no local de trabalho; mantém vigilância ostensiva no local de trabalho ou se apodera de documentos ou objetos pessoais do trabalhador, com o fim de retê-lo no local de trabalho. A pena é aumentada de metade, se o crime é cometido: contra criança ou adolescente; por motivo de preconceito de raça, cor, etnia, religião ou origem. 
Art. 203 - Frustrar, mediante fraude ou violência, direito assegurado pela legislação do trabalho. Pena: detenção, de um ano a dois anos, e multa, além da pena correspondente à violência. Na mesma pena incorre quem: obriga ou coage alguém a usar mercadorias de determinado estabelecimento, para impossibilitar o desligamento do serviço em virtude de dívida; impede alguém de se desligar de serviços de qualquer natureza, mediante coação ou por meio da retenção de seus documentos pessoais ou contratuais. A pena é aumentada de um sexto a um terço se a vítima é menor de dezoito anos, idosa, gestante, indígena ou portadora de deficiência física ou mental.

Art. 207 - Aliciar trabalhadores, com o fim de levá-los de uma para outra localidade do território nacional. Pena: detenção, de um a três anos, e multa. Incorre na mesma pena quem recrutar trabalhadores fora da localidade de execução do trabalho, dentro do território nacional, mediante fraude ou cobrança de qualquer quantia do trabalhador, ou, ainda, não assegurar condições do seu retorno ao local de origem. A pena é aumentada de um sexto a um terço se a vítima é menor de dezoito anos, idosa, gestante, indígena ou portadora de deficiência física ou mental (Brasil, 1940).

A Constituição Federal (CF) brasileira define, em seu Art. 186, a função social da propriedade rural tendo como princípio o aproveitamento racional do imóvel, a utilização adequada dos recursos naturais, a observância das relações de trabalho e exploração voltada ao bem-estar dos proprietários e dos trabalhadores. Portanto, a 
propriedade privada é passível de desapropriação por descumprimento da função social trabalhista.

Apesar desta situação estar prevista na CF, o Projeto de Emenda Constitucional 438/01 - conhecido como "PEC do Trabalho Escravo" -, que tramita no Congresso, desde 1995, prevê o confisco da propriedade onde for constatada a exploração de mão de obra em condições análogas a de escravo, além de sua destinação para a reforma agrária, caso seja no campo, e programas de moradia popular, se for encontrado nas áreas urbanas.

Desde 1999, a bancada ruralista apresenta empecilhos à aprovação da PEC do Trabalho Escravo e, no dia 22 de maio de 2012, foi aprovada, em primeiro turno, na Câmara de Deputados. Porém, sua aprovação foi condicionada a elaboração de uma legislação específica com relação à conceituação e que diferencie "desrespeito a legislação trabalhista" e "condição análoga a de escravo".

A proposta da bancada ruralista é um projeto que defina "claramente" trabalho escravo. O PL 3842/2012, que propõe alterar o art. 149 do Código Penal, retirando termos caros para o avanço do combate ao trabalho análogo a de escravo no Brasil como "jornada exaustiva", "condições degradantes de trabalho" e "preposto" e incluem a necessidade de ameaça, coação e violência para a caracterização do trabalho escravo. A proposta vincula, ainda, a intenção clara de uma pessoa submeter à outra ao trabalho análogo à de escravo, punindo quem "dolosamente" cercear o uso de qualquer meio de transporte ao trabalhador, com o fim de retê-lo no local de trabalho; ou mantiver vigilância ostensiva, com essa mesma finalidade, "comprovadamente". Entende-se que o artigo 149 do Código Penal já descreve claramente o trabalho análogo a de escravo e que esta proposta tem a intenção de garantir a permanência de condições inaceitáveis de exploração do homem sobre seu semelhante. 
No Brasil, desde 2002, o trabalhador identificado como submetido a regime de trabalho forçado ou reduzido a condição análoga a de escravo tem direito a três parcelas de seguro desemprego especial no valor de um salário mínimo cada. O seguro desemprego especial foi criado, em 2002, pela Lei no 10.608. Infelizmente, não é condição suficiente para que os trabalhadores resgatados possam reconstruir suas vidas em moldes diferentes, garantindo melhores condições e até mesmo o não aliciamento reincidente.

\section{Perfil do trabalhador resgatado}

Com base na lista do seguro desemprego especial é possível traçar um perfil do trabalhador resgatado, em especial quanto a sua origem, por gênero, grau de instrução e raça/cor. Assim, tem-se que, no período de 2003 a 2012, 28.170 trabalhadores foram resgatados que receberam seguro desemprego no Brasil, e destes, 2.007, correspondendo a 7,12\%, são trabalhadores com residência na Bahia.

Na Tabela 6 constam, sistematizadas, as informações sobre os trabalhadores que receberam o seguro desemprego especial o que permite identificar sua origem segundo Território de Identidade.

Tabela 6 Seguro desemprego especial por Território de Identidade. Bahia, 2003 a 2012

\begin{tabular}{lccc}
\hline \multicolumn{1}{c}{ Território de Identidade } & Resgatados & $\mathbf{\%}$ & \% acumulado \\
\hline Bacia do Rio Grande & 545 & 27,2 & 27,2 \\
Irecê & 221 & 11,0 & 38,2 \\
Sertão Produtivo & 173 & 8,6 & 46,8 \\
Baixo Sul & 146 & 7,3 & 54,1
\end{tabular}

Brasiliana - Journal for Brazilian Studies. Vol. 2, n.2 (Nov 2013). ISSN 2245-4373. 


\begin{tabular}{|c|c|c|c|}
\hline Velho Chico & 145 & 7,2 & 61,3 \\
\hline Bacia do Rio Corrente & 105 & 5,2 & 66,5 \\
\hline Sisal & 79 & 3,9 & 70,5 \\
\hline Recôncavo & 79 & 3,9 & 74,4 \\
\hline Chapada Diamantina & 59 & 2,9 & 77,3 \\
\hline Piemonte Norte do Itapicuru & 58 & 2,9 & 80,2 \\
\hline Piemonte do Paraguaçu & 54 & 2,7 & 82,9 \\
\hline Portal do Sertão & 47 & 2,3 & 85,3 \\
\hline Vitória da Conquista & 44 & 2,2 & 87,4 \\
\hline Piemonte da Diamantina & 43 & 2,1 & 89,6 \\
\hline Semiárido Nordeste II & 35 & 1,7 & 91,3 \\
\hline Extremo Sul & 31 & 1,5 & 92,9 \\
\hline Litoral Sul & 24 & 1,2 & 94,1 \\
\hline Costa do Descobrimento & 23 & 1,1 & 95,2 \\
\hline Litoral Norte e Agreste Baiano & 17 & 0,8 & 96,1 \\
\hline Sertão do São Francisco & 15 & 0,7 & 96,8 \\
\hline Metropolitana de Salvador & 14 & 0,7 & 97,5 \\
\hline Itaparica & 12 & 0,6 & 98,1 \\
\hline Bacia do Jacuipe & 10 & 0,5 & 98,6 \\
\hline Bacia do Paramirim & 9 & 0,4 & 99,1 \\
\hline Médio Rio de Contas & 9 & 0,4 & 99,5 \\
\hline Vale do Jiquiriça & 7 & 0,3 & 99,9 \\
\hline Medio Sudoeste da Bahia & 3 & 0,1 & 100,0 \\
\hline Total & 2.007 & 100,0 & \\
\hline
\end{tabular}

Fonte: Elaborado com Base DES/TEM, 2003-2012.

Os Territórios de Identidade Bacia do Rio Corrente e Bacia do Rio Grande concentram mais de 30\% dos trabalhadores resgatados com residência na Bahia que receberam seguro desemprego. Destes, $27 \%$ tem residência de origem no Território de Identidade Bacia do Rio Grande e todos os 14 municípios deste Território tiveram resgatados que receberam seguro desemprego. Mais da metade dos 545 resgatados da Bacia do Rio Grande tem residência nos municípios de Barreiras e Luis Eduardo Magalhães. Depois da Bacia do Rio Grande, o Território de Identidade Irecê é 
a qu e le que mais apresenta trabalhadores resgatados (Figura 2).

\section{Figura 2}

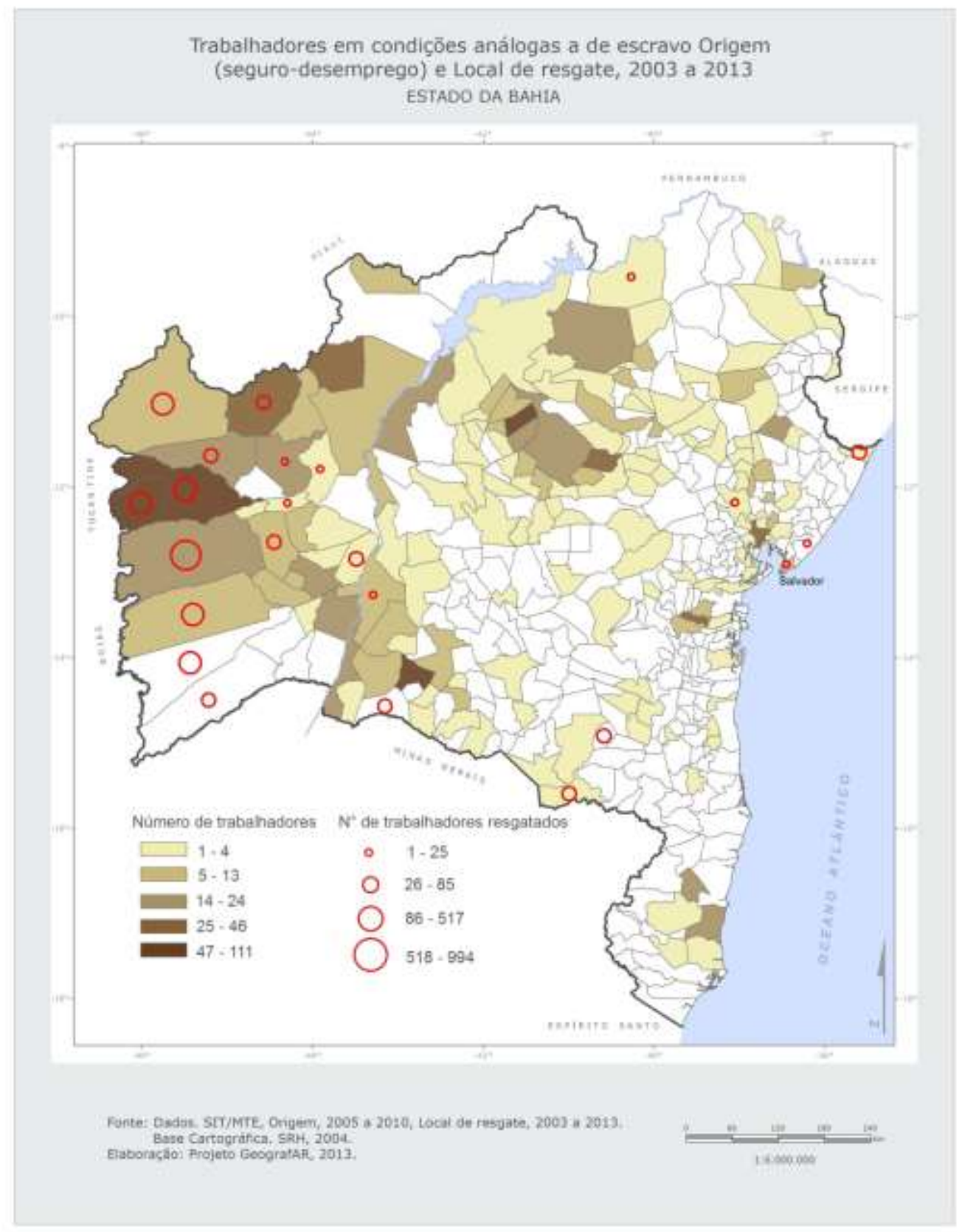

A análise dos dados do seguro desemprego permite identificar alguns traços do perfil

Brasiliana - Journal for Brazilian Studies. Vol. 2, n.2 (Nov 2013). ISSN 2245-4373. 
dos trabalhadores resgatados. No recorte de gênero tem-se que, cerca de $96 \%$ dos regatados são homens e 4\% mulheres. Os dados apontam para uma concentração de mulheres resgatadas na Bacia do Rio Grande e no Sertão Produtivo, conforme Tabela 7.

Tabela 7 Distribuição por gênero dos trabalhadores que receberam seguro-desemprego especial, por Território de Identidade. Bahia, 2003 a 2012.

\begin{tabular}{|c|c|c|}
\hline \multirow[b]{2}{*}{ Território de Identidade } & \multicolumn{2}{|c|}{ Resgatados } \\
\hline & Homens & Mulheres \\
\hline Irecê & 218 & 3 \\
\hline Velho Chico & 137 & 8 \\
\hline Chapada Diamantina & 58 & 1 \\
\hline Sisal & 78 & 1 \\
\hline Litoral Sul & 24 & 0 \\
\hline Baixo Sul & 141 & 5 \\
\hline Extremo Sul & 31 & 0 \\
\hline Medio Sudoeste da Bahia & 3 & 0 \\
\hline Vale do Jiquiriça & 7 & 0 \\
\hline Sertão do São Francisco & 15 & 0 \\
\hline Bacia do Rio Grande & 521 & 24 \\
\hline Bacia do Paramirim & 9 & 0 \\
\hline Sertão Produtivo & 159 & 14 \\
\hline Piemonte do Paraguaçu & 54 & 0 \\
\hline Bacia do Jacuipe & 10 & 0 \\
\hline Piemonte da Diamantina & 42 & 1 \\
\hline Semiárido Nordeste II & 35 & 0 \\
\hline Litoral Norte e Agreste Baiano & 15 & 2 \\
\hline Portal do Sertão & 47 & 0 \\
\hline Vitória da Conquista & 37 & 7 \\
\hline Recôncavo & 79 & 0 \\
\hline Médio Rio de Contas & 8 & 1 \\
\hline Bacia do rio corrente & 104 & 1 \\
\hline Itaparica & 12 & 0 \\
\hline Piemonte Norte do Itapicuru & 58 & 0 \\
\hline RMS & 12 & 2 \\
\hline Costa do Descobrimento & 19 & 4 \\
\hline Total & 1.933 & 74 \\
\hline
\end{tabular}

Fonte: Elaborado com Base DES/MTE, 2003-2012.

Brasiliana - Journal for Brazilian Studies. Vol. 2, n.2 (Nov 2013). ISSN 2245-4373. 
Com relação ao grau de instrução, tem-se que dos resgatados, com residência na Bahia, praticamente $80 \%$ tinha até o $5^{\circ}$ ano completo. Esse percentual varia pouco quando a análise leva em consideração o gênero. Das mulheres, mais de $75 \%$ tinham até o 5 o ano incompleto e os homens $72 \%$ (Tabela 8 e Gráfico 1).

Tabela 8 Grau de instrução dos trabalhadores resgatados, Bahia, 2003 a 2012

\begin{tabular}{lrrrrrr}
\hline \multicolumn{1}{c}{ Grau de instrução } & \multicolumn{3}{c}{ Feminino } & \multicolumn{3}{c}{ Masculino } \\
& no & $\%$ & acum. & no & $\%$ & acum. \\
\hline Analfabeto & 21 & 28,77 & 28,77 & 528 & 28,21 & 28,21 \\
Até 5o ano incompleto & 35 & 47,95 & 76,71 & 811 & 43,32 & 71,53 \\
$5^{\mathbf{o}}$ ano completo & 2 & 2,74 & 79,45 & 26 & 1,39 & 72,92 \\
5o ao 9o ano incompleto & 8 & 10,96 & 90,41 & 350 & 18,70 & 91,61 \\
Fundamental completo & 2 & 2,74 & 93,15 & 93 & 4,97 & 96,58 \\
Ensino Médio incompleto & 4 & 5,48 & 98,63 & 22 & 1,18 & 97,76 \\
Ensino Médio completo & 0 & 0,00 & 98,63 & 41 & 2,19 & 99,95 \\
Superior incompleto & 1 & 1,37 & 100,00 & 1 & 0,05 & 100,00 \\
Total & $\mathbf{7 3}$ & $\mathbf{1 0 0 , 0 0}$ & & $\mathbf{1 . 8 7 2}$ & $\mathbf{1 0 0 , 0 0}$ & \\
\hline
\end{tabular}

Fonte: Elaborado com Base DES/MTE, 2003-2012.

Gráfico 1 - Grau de instrução dos trabalhadores resgatados, Bahia, 2003 a 2012

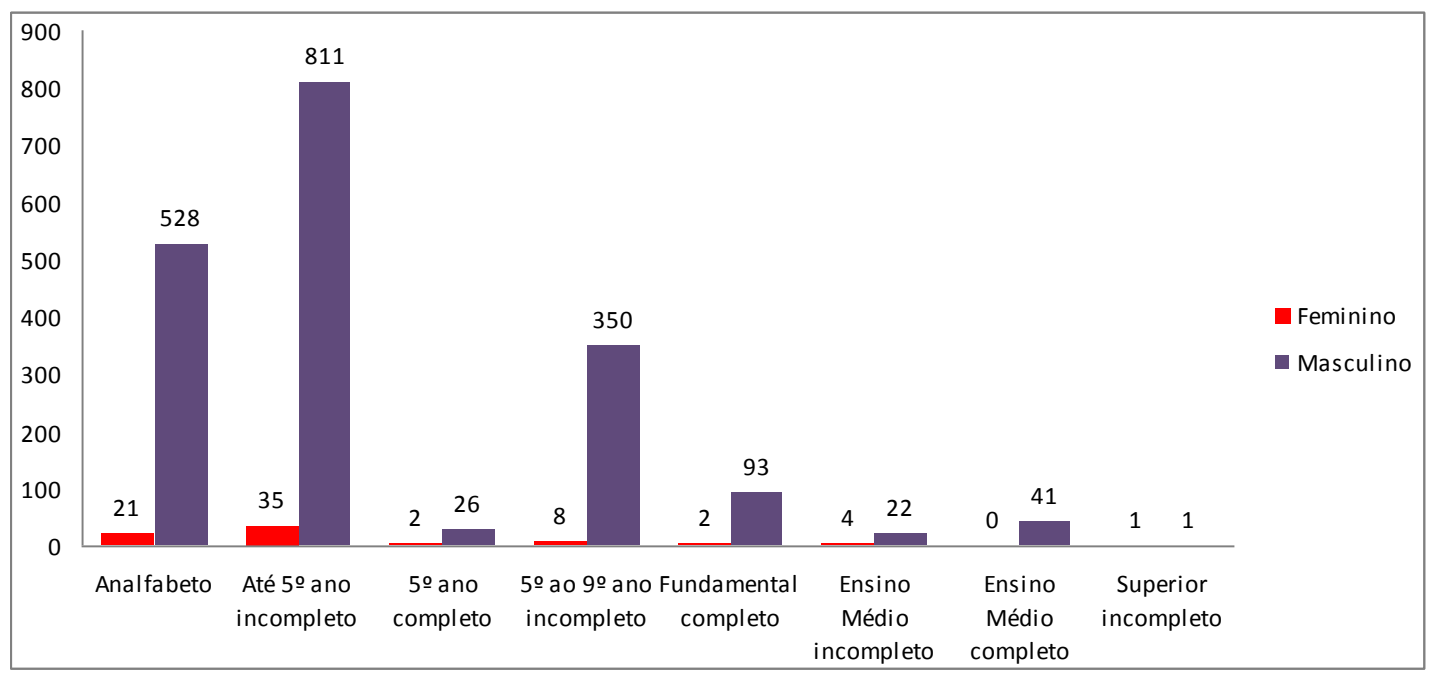

Fonte: Elaborado com Base DES/MTE, 2003-2012.

Brasiliana - Journal for Brazilian Studies. Vol. 2, n.2 (Nov 2013). ISSN 2245-4373. 
Na Tabela 9 e no Gráfico 2 constam a distribuição dos trabalhadores resgatados segundo raça/cor. Esta informação é obtida através de declaração do próprio trabalhador. Cabe observar que 39,1\% dos trabalhadores resgatados se declararam como sendo da raça/cor mulata ${ }^{14} ; 27,1 \%$ como amarela ${ }^{15}$; $19 \%$ como preta; e aproximadamente $14,7 \%$ como branca. Há um caso de indígena entre os trabalhadores resgatados.

Tabela 9 Trabalhadores resgatados segundo declaração de raça/cor. Bahia, 2003 a 2012

\begin{tabular}{lrr}
\hline \multicolumn{1}{c}{ Raça/cor } & \multicolumn{1}{c}{ Total } & \multicolumn{1}{c}{ \% } \\
\hline Branca & 69 & 14,7 \\
Amarela & 127 & 27,1 \\
Indígena & 1 & 0,2 \\
Mulata & 183 & 39,1 \\
Preta & 88 & 18,8 \\
Total & $\mathbf{4 6 8}$ & $\mathbf{1 0 0 , 0 0}$ \\
\hline
\end{tabular}

Fonte: Elaborado com Base DES/MTE, 2003-2012

Gráfico 2 - Trabalhadores resgatados segundo declaração de raça/cor. Bahia, 2003 a 2012

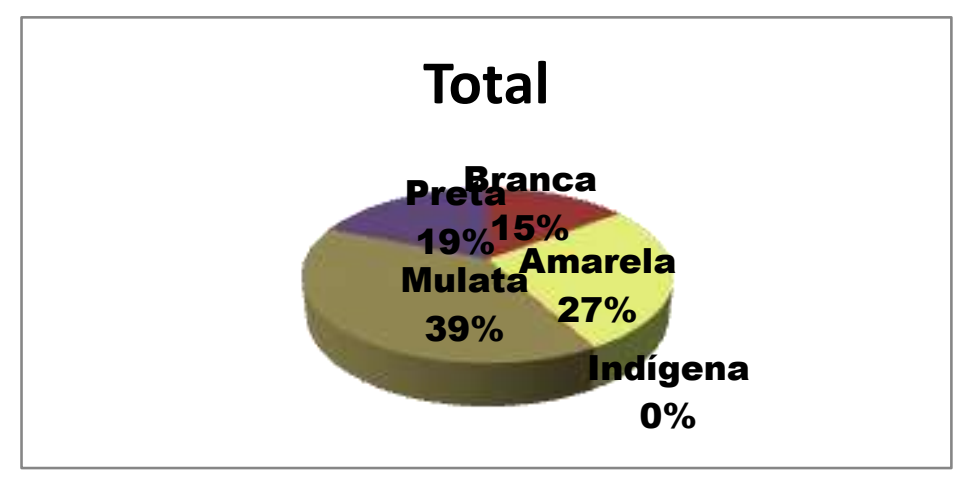

Fonte: Elaborado com Base DES/MTE, 2003-2012

\footnotetext{
${ }^{14}$ Mulata, Cabocla, Cafuza, Mameluca ou Mestiça de Preto com Pessoa de Outra Cor ou Raça

${ }^{15}$ De origem Japonesa, Chinesa, Coreana, etc;
}

Brasiliana - Journal for Brazilian Studies. Vol. 2, n.2 (Nov 2013). ISSN 2245-4373. 
Após o seguro desemprego, os trabalhadores resgatados continuam em situação de vulnerabilidade, passíveis de serem aliciados novamente.

Em relação a qualquer outro benefício não há em nosso estado nenhuma prioridade aos trabalhadores resgatados na obtenção desses benefícios. Entendemos que após o relatório de fiscalização, deveria ser ao menos catalogado o município de origem dos trabalhadores resgatados e encaminhada à informação às secretárias municipais de Assistência Social para que possam garantir a inclusão em algum programa e mesmo garantir um acompanhamento para que ele não seja novamente vitima desse crime (CDVDH/CB, 2011, p. 102).

Na Bahia, a Secretaria de Desenvolvimento Social e Combate a Pobreza é responsável pelo acordo de cooperação firmado entre o Ministério do Desenvolvimento Social e Combate à Fome (MDS) e o Ministério do Trabalho e Emprego (MTE), para que os resgatados do trabalho escravo sejam incluídos no Cadastro Único para programas sociais do governo federal, e se tornem grupo prioritário para receber os benefícios. Para além de possibilitar que políticas de proteção e de promoção social sejam destinados para esse grupo, o acompanhamento do CadÚnico permite saber onde estão aqueles resgatados de acordo com o período de acompanhamento dos programas sociais. Esta cooperação, no entanto, ainda não vem sendo de fato efetivada na Bahia. Porém, esta medida se apresenta como um mínimo reparo feito pelo Estado de um crime, definido pelo Código Penal, de exploração do homem pelo homem inaceitável em nossa sociedade. Assim todo direito deve ser garantido, mas qualquer tipo de programa de reparação não pode se apresentar como algo estrutural na sociedade brasileira com o risco de se assegurar a manutenção da 
situação degradante posta.

\section{Considerações Finais}

Buscou-se nesse estudo verificar de que maneira a expansão da fronteira agrícola se relaciona com o trabalho análogo a de escravo no Oeste da Bahia. A alta concentração da propriedade da terra revela uma situação de vulnerabilidade propícia a conflitos e exploração, pois está diretamente relacionada às limitadas ocupações e empregos no campo. A baixa oferta de trabalho no campo abre espaço para a exploração dos trabalhadores em sua expressão mais degradante: o trabalho análogo a de escravo. $\mathrm{O}$ trabalhador submetido a condições degradantes de trabalho é o mesmo sujeito que é expulso de sua terra pela expansão do capital no campo, pela concentração de terras, pela impossibilidade de se reproduzir socialmente em minifúndios ou que é atraído pelas "oportunidades" idealizadas nas cidades "desenvolvidas".

$\mathrm{Na}$ análise dos casos de ocorrência de trabalho escravo na Bahia verificou-se a correlação com a concentração da propriedade da terra e, em especial, como coexistem com as atividades de ponta do modelo agrícola nacional: o agronegócio. Nos municípios do Oeste baiano onde houve resgates de trabalhadores em condições análogas a de escravo, contatou-se expansão da fronteira agrícola paralelo com aumento da concentração de terras. Os dados do Censo Agropecuário revelaram elevação na concentração de terras nas propriedades acima de 500 hectares. Os dados da PAM revelaram expansão da fronteira agrícola nesses municípios, mais concentrada e com ampliação das culturas do algodão herbáceo, milho e da soja. Culturas estas com maior incidência de trabalho escravo.

Trabalho escravo no Brasil nunca foi exceção, ele não deixou de existir com a assinatura de uma lei, em 1888. A escravidão contemporânea traz elementos de 
adaptação ao modo de produção capitalista, pois se não há mais grilhões da antiga escravidão, a crueldade da escravidão contemporânea se revela ainda mais lucrativa, dado que o trabalhador não tem custo elevado para ser "contratado" e, na maioria das vezes, não tem ligação com o local de trabalho. $\mathrm{O}$ contingente de trabalhadores em condições de vulnerabilidade permite o sistema de descarte quando for conveniente: quando o trabalhador estiver doente, ou quando estiver em períodos de entre safra, por exemplo.

A legislação brasileira é avançada no que diz respeito ao trabalho análogo a de escravo, mas combatê-lo, no Brasil é, para além da legislação trabalhista, enfrentar o grande latifúndio. Não basta resgatar, é preciso criar condições para que estes trabalhadores possam ser reinseridos de forma digna na sociedade e no mercado de trabalho. A aprovação da PEC do trabalho escravo e a manutenção do conceito de trabalho análogo a de escravo definido pelo Código Penal é imprescindível para o Brasil avançar no combate ao trabalho escravo contemporâneo no território nacional. O desafio imposto pela bancada ruralista é o de não retroceder na questão de garantia de direitos trabalhistas e proteção à dignidade humana. A propriedade que não cumpre sua função social deve ser expropriada e revertida para reforma agrária, não há avanço trazido pelo agronegócio e pela concentração de terras, se onde eles imperam há miséria e degradação humana. É preciso fazer a reforma agrária, já!

\section{Referências}

Bahia. SEAGRI. Nota Técnica Região Oeste da Bahia. s/d. Disponível em: http://www.seagri.ba.gov.br/nota_tecnica_regiao_oeste.pdf. Acesso em: 02 ago 2013.

Brasil. Lei $\quad n^{\circ} 10.803 ; \quad 2003 ; \quad$ Disponível em: http://www.planalto.gov.br/ccivil_03/Leis/2003/ L10.803.htm. Acesso em: 23 jan 2013. 
Brasil. Código Penal. 1940. Disponível em: < http://www.planalto.gov.br/ccivil_03/decreto-lei/del2848.htm>. Acesso em: 02 ago 2013.

Brasil. Ministério do Trabalho e Emprego. Cadastro de empresas e pessoas autuadas por exploração do trabalho escravo. 2012. Disponível em: < http://portal.mte.gov.br/trab_escravo/ portaria-do- mte-cria-cadastro-de-empresase- pessoas-autuadas-por-exploracao-do-trabalho-escravo.htm>

Centro de Defesa da Vida e dos Direitos Humanos Carmen Bascarán (CDVDH/CB). Atlas Político-Jurídico do Trabalho Escravo contemporâneo no Maranhão. Imperatriz (MA): Ética, 2011.

DES/MTE. Ministério do Trabalho e Emprego. Departamento de Emprego e Salário. Seguro Desemprego Especial Trabalho Escravo. Período 2003 a 2012.

GERMANI, Guiomar Inez. Condições históricas e sociais que regulam o acesso a terra no espaço agrário brasileiro. GeoTextos: revista da Pós-Graduaçào em Geografia da Universidade Federal da Bahia/Instituto de Geociências. V1, N.1. Salvador: Programa de Pós-Graduação em geografia,2005. p. 115-147.

Germani, Guiomar Inez. Questão Agrária e Movimentos Sociais: a territorialização da luta pela terra na Bahia. In: Coelho Neto, A et. Al. (orgs). (GEO) grafias dos Movimentos Sociais. Feira de Santana: UEFS, 2010, p. 269-304.

IBGE. Pesquisa Agrícola Municipal. Disponível em: http://www.ibge.gov.br/home/estatistica/economia/pam/, Acesso em: 02 ago 2013.

IBGE. Censo Agropecuário. Disponível em: http://www.ibge.gov.br/home/estatistica/economia/agropecuaria/censoagro/. Acesso em 02 ago 2013.

Mendonça, Jackson Ornelas. O potencial de crescimento da produção de grãos no Oeste da Bahia. In: Bahia Agrícola, v.7, n.2. 2006.

Nery, Hernane Magalhães; Germani, Guiomar Inez; Oliveira, Gilca Garcia. Fronteira Agrícola da Bahia: Plantando Relações de Trabalho Análogas à Escravidão. In: Anais do 
XXVIII Congresso Internacional da Associação Latino-Americana de Sociologia (ALAS), 2011, Recife (PE). 2011. Disponível em:< http://www.geografar.ufba.br/site/main.php?page=bib-publicacoes $>$. Acesso em: 02 Set 2013.

Oliveira, Gilca Garcia; Germani, Guiomar Inez; Sampaio, Jose Levi Furtado; Nery, Hernane Magalhães. Trabalho Análogo a Escravo: Um debate necessário. Bahia. 2011.

Santos, Laiana Carolina Silva; Oliveira, Gilca Garcia. Trajetórias do Setor Rural Baiano: Uma Análise de Indicadores. SOBER. 2012. 